\title{
BMJ Open Prevalence of obesity and affecting factors in physically disabled adults living in the city centre of Malatya
}

\author{
Çiğdem Bozkir, ${ }^{1}$ Ali Özer, ${ }^{2}$ Erkan Pehlivan ${ }^{2}$
}

To cite: Bozkir Çiğdem, Özer A, Pehlivan E. Prevalence of obesity and affecting factors in physically disabled adults living in the city centre of Malatya. BMJ Open 2016;6:e010289. doi:10.1136/bmjopen-2015010289

- Prepublication history for this paper is available online To view these files please visit the journal online (http://dx.doi.org/10.1136/ bmjopen-2015-010289).

Received 20 October 2015 Revised 23 May 2016 Accepted 22 July 2016

\section{CrossMark}

\footnotetext{
${ }^{1}$ T.R. Ministry of Health, Provincial Directorate of Public Health Obesity Unit, Malatya, Turkey

${ }^{2}$ Department of Public Health, Medicine School, Inonu University, Malatya, Turkey

Correspondence to Çiğdem Bozkir; bozkircigdem@windowslive. com
}

\section{ABSTRACT}

Objective: The purpose of this study was to investigate the prevalence of obesity, and the risk factors associated with it, in physically disabled adults living in the city centre of Malatya, Turkey.

Method: This research was designed as a crosssectional study conducted on physically disabled people aged 20-65 years living in the city centre of Malatya. The prevalence of obesity in disabled people was within $95 \% \mathrm{Cls}$, the power was calculated as $80 \%$, and the sample size of our population was calculated as 258 individuals.

Results: The prevalence of obesity was found to be $13.2 \%$. The relationship between disability type and obesity status was found to be significant. The prevalence of obesity was $21.3 \%$ in visually impaired people, $17.9 \%$ in speech-impaired people, $17.8 \%$ in hearing-impaired people and $6.5 \%$ in orthopaedically disabled people.

Conclusions: Educational interventions on nutrition and lifestyle can be effective considering the high prevalence of obesity in visually impaired people, the prevalence of weakness in orthopaedically disabled people and the risk related to the area in which body fat is localised even when body mass index is within the normal range. Training disabled people in sports appropriate to their disability type and building appropriate facilities for those sports might have a positive effect.

\section{INTRODUCTION}

The WHO describes obesity as abnormal and excessive accumulation of fat in the body that can be harmful to human health. ${ }^{1}$ Epidemiological studies have shown that biological factors and lifestyle factors, such as nutritional habits, cigarette smoking, alcohol consumption and lack of physical activity, are responsible for obesity. Furthermore, demographic factors, such as age and gender, and sociocultural factors, such as educational level and marital status, also have an effect. ${ }^{2}$

Type 2 diabetes mellitus, hypertension, dyslipidaemia and cardiovascular disease are the most important disorders caused by obesity;

\section{Strengths and limitations of this study}

- Excluding mentally disabled people because of the difficulty of communication is a limitation of this study.

- No studies of this type have been carried out in Turkey before and there are inadequate numbers of similar studies in the literature.

- Obesity further restricts the living space of disabled people and so this topic is significant.

these diseases result in high morbidity and mortality. In addition, obesity contributes to predisposing factors in some types of cancer. ${ }^{3}$ It is also considered to be a psychosomatic disease by some researchers. ${ }^{4}$

Disability can cause the development of obesity by limiting physical activity. The description of 'disabled' accepted by the United Nations General Assembly is: 'people who cannot perform the activities that a normal person should be able to do in his/ her personal or social life by himself/herself due to a deficiency resulting from a hereditary or acquired abnormality in their physical or mental status'. The WHO describes 'disability' as a disadvantaged condition that occurs for a specific individual as a result of deficiency and that limits and prevents the individual's ability to perform activities that can be considered routine according to his or her age, gender and social and cultural situation. $^{5}$ According to $\mathrm{WHO}$ data, $10 \%$ of the world's population is disabled. ${ }^{6}$ The Turkey Disability Survey reported that the proportion of the total population that is disabled is $12.3 \%$; this means that there are about 8.5 million disabled people in Turkey. ${ }^{7}$

Disability is a problem that affects not only the individual with the difficulty, but also their family and their immediate society in economic, social and psychological ways. ${ }^{8}$ As obesity brings with it many health problems, obesity in disabled people should be prevented, since it will further restrict an already 
limited life capacity and increase the disease burden. ${ }^{9}$

No studies of this type have been carried out in our country, and few studies have been published at all. Obesity further restricts the living space of the disabled and causes many health problems. ${ }^{2}$ Accordingly, the aim of this study was to investigate the obesity level of physically disabled adults and the risk factors associated with obesity in the city centre of Malatya, Turkey.

\section{MATERIALS AND METHODS}

This research was designed as a cross-sectional study, and it included physically disabled people aged 2065 years living in the city centre of Malatya. Approval for the research was obtained from the ethics committee at the İnönü University Faculty of Medicine. Participants provided written informed consent to participate. The expected number of disabled people in Malatya is 12387 , as the population of the city centre is $480144 .^{10}$ For calculation of the size of the sample, the prevalence of obesity in the disabled was taken as $9.5 \%,{ }^{11}$ with $95 \%$ CIs, $80 \%$ power and 258 individuals.

The research data were collected between August and December 2011. To collect the data, we used the list of 595 disabled people registered with the Malatya Municipality City Council Disabled People Centre and selected 258 using the systematic sampling method, 124 of whom were orthopaedically disabled, 61 were visually impaired, 45 were hearing impaired, and 28 were speech impaired. To determine the personal characteristics of the participants, a questionnaire was filled out by the researcher using the face-to-face interview method. Information on demographic characteristics (age, gender, marital status, educational level, occupation and social security status), cigarette and alcohol consumption, and lifestyle was collected using the questionnaire. To verify the functionality of the questions, a pretest was implemented using the questionnaire on a population of 10 physically disabled people. After the pretest, any necessary corrections were made and the questionnaire was finalised.

\section{Nutritional Habits Index}

Nutritional habits were measured using the 'Nutritional Habits Index' (NHI), which was developed and revised by Demirezen and Coşansu ${ }^{12}$ and consists of six items. The intervals that formed according to the total score obtained from NHI were considered to be the nutritional habits risk level. According to the total score obtained from the NHI, nutritional habits risk levels were considered as follows: 0 , no risk; $1-6$, slight risk; 712, intermediate risk; $13-18$, high risk; and 19-24, very high risk. ${ }^{13}$

\section{Dutch Eating Behaviour Questionnaire}

Emotional eating behaviour-a sub-scale of the Dutch Eating Behaviour Questionnaire (DEBQ), which consists of 13 questions-was used to measure the eating habits of the participants. The items on the questionnaire were measured with a five-point Likert scale: 1, never; 2, rarely; 3, sometimes; 4, often; 5 , very often. A choice of 'there is no interest' was also presented for the items. The DEBQ was developed by Van Strein et $a l^{14}$ in 1986. Turkish validity and reliability studies were conducted by Bozan with a population of university students. ${ }^{15}$

\section{Nottingham Health Profile}

The Nottingham Health Profile (NHP) was developed in the Department of Public Health at the Nottingham University Faculty of Medicine in $1975 .{ }^{16}$ In this questionnaire, patients are asked to respond to the questions with 'Yes' or 'No'. The instrument consists of six parts and a total of 38 questions. Eight questions relate to pain and physical activity, five to sleep, three to tiredness, five to social isolation, and nine to emotional reactions. ${ }^{17} 18$

According to the method developed by Alonso et al, NHP scores are calculated as follows: 'No' answers from all questions in one dimension are scored with 1 and 'Yes' answers from all questions are scored with $0 .{ }^{19} \mathrm{Next}$, the total number of positive answers in each dimension is divided by the total number of questions in that dimension, and then the result obtained is multiplied by 100 . Consequently, probable results between 0 and 100 are obtained. A score approaching 100 expresses low perceived health status. ${ }^{20}$ Adaptation of the NHP and its psychometric characteristics to a Turkish population was performed by Küçükdeveci et al. ${ }^{17}$

\section{Anthropometric measurements}

Height and weight of the participants were measured in order to calculate their body mass index (BMI). Height was measured in participants with bare feet juxtaposed to each other, with the back of the head, dorsa, buttocks and back of the heels leaning against a flat wall, standing upright and from the top of the head to the soles of the feet. Weight of participants who did not have a disability that prevented them from standing was measured with platform scales sensitive to $0.1 \mathrm{~kg}$. While measurements were taken, clothes had to be as thin as possible and the feet had to be bare. Waist circumference was measured with a tape measure from the lowest rib to the middle point of the distance between the crista iliaca anterior superior. Height and waist circumference were measured to the nearest centimetre. To prevent variation between participants, measurements were taken by one researcher. BMI was calculated by dividing body weight in kilograms by the square of body height in metres. BMI and waist circumference were evaluated according to the WHO classification. ${ }^{21}$

Upper arm circumference, knee-deep and waist circumference of orthopaedically disabled participants who could not stand were measured to obtain height and weight. The results of these measurements were put in the formulas in table 1 and the heights and weights of the participants were determined. ${ }^{22}$ 
Table 1 Determination of height and body weight of orthopaedically disabled and bedridden patients (aged between 19 and 80$)^{22}$

\begin{tabular}{lll}
\hline Age (years) & Male & Female \\
\hline Height & & \\
$19-59$ & $(\mathrm{KD} \times 1.88)+71.85$ & $(\mathrm{KD} \times 1.86)-(\mathrm{A} \times 0.05)+70.25$ \\
$60-80$ & $(\mathrm{KD} \times 2.08)+59.01$ & $(\mathrm{KD} \times 1.91)-(\mathrm{A} \times 0.17)+75.00$ \\
Body weight & $(\mathrm{KD} \times 1.19)+(\mathrm{AC} \times 3.21)-86.82$ & $(\mathrm{KD} \times 1.01)+(\mathrm{AC} \times 2.81)-66.04$ \\
$19-59$ & $(\mathrm{KD} \times 1.10)+(\mathrm{AC} \times 3.07)-75.81$ & $(\mathrm{KD} \times 1.09)+(\mathrm{AC} \times 2.68)-65.51$ \\
$60-80$ & &
\end{tabular}

\section{Evaluation of data}

All the data obtained from the research was evaluated using SPSS 15.0 for Windows. Appropriate descriptive values were given for qualitative and quantitative variables. Qualitative variables were expressed as number (\%); quantitative variables with normal distribution were expressed as mean $\pm \mathrm{SD}$ and those that were not normally distributed were expressed as minimum, median and maximum. The Kolmogorov-Smirnov test determined that the data on age and BMI, which were obtained by measurement, were normally distributed $(p>0.05)$, and the other data were not $(p<0.05)$. For analysis of qualitative data, the Mann-Whitney $U$ test and Kruskal-Wallis test, which are non-parametric tests, and a Bonferroni-corrected Mann-Whitney U test, as a post hoc test, were used. For analysis of quantitative data, the Pearson $\chi^{2}$ and Fisher exact tests were used. $\mathrm{p}<0.05$ was accepted as significant in all statistical evaluations.

\section{RESULTS}

The gender distribution of the participants was $28.7 \%$ female and $71.3 \%$ male. Their ages ranged between 20 and 65 years $($ mean \pm SD $38.1 \pm 10.4)$. It was observed that $43 \%$ of the participants had disabilities in the range 26$50 \%$, and $11.3 \%$ had disabilities at $25 \%$ or below. With regard to marital status, $52.7 \%$ of the participants were married, $38.8 \%$ were single and $8.5 \%$ were widowed. It was found out that $18.2 \%$ of the sample did not graduate from any school, 29.8\% graduated from elementary school, $38.0 \%$ graduated from secondary school, and $14.0 \%$ had an associate or bachelor degree. Analysis of social security status showed that $50 \%$ had insurance from the Social Security Institution (SSI) and $8.5 \%$ had no social security (table 2 ).

Analysis of the habits of the sample according to disability type showed that the difference between the participants who smoked and those who did not was not significant $(p>0.05)$. It was observed that $71 \%$ of the orthopaedically disabled participants, $86.9 \%$ of the visually impaired participants, $73.3 \%$ of the hearing impaired participants, and $75 \%$ of the speech impaired participants did not do any exercise, and the differences were found to be significant $(\mathrm{p}<0.05)$.

\begin{tabular}{|c|c|c|}
\hline Characteristic & $\mathbf{n}$ & $\%$ \\
\hline \multicolumn{3}{|l|}{ Gender } \\
\hline Male & 184 & 71.3 \\
\hline Female & 74 & 28.7 \\
\hline \multicolumn{3}{|l|}{ Age (years) } \\
\hline $20-24$ & 23 & 8.9 \\
\hline $25-29$ & 38 & 14.7 \\
\hline $30-34$ & 42 & 16.3 \\
\hline $35-39$ & 45 & 17.4 \\
\hline 40 or above & 110 & 42.6 \\
\hline \multicolumn{3}{|l|}{ Disability type } \\
\hline Orthopaedic & 124 & 48.1 \\
\hline Visual & 61 & 23.6 \\
\hline Hearing & 45 & 17.4 \\
\hline Motor Speech & 28 & 10.9 \\
\hline \multicolumn{3}{|l|}{ Disability proportion } \\
\hline $0-25$ & 29 & 11.3 \\
\hline $26-50$ & 111 & 43.0 \\
\hline $51-75$ & 69 & 26.7 \\
\hline $76-100$ & 49 & 19.0 \\
\hline \multicolumn{3}{|l|}{ Marital status } \\
\hline Married & 136 & 52.7 \\
\hline Single & 100 & 38.8 \\
\hline Widowed & 22 & 8.5 \\
\hline \multicolumn{3}{|l|}{ Educational level } \\
\hline Below elementary & 47 & 18.2 \\
\hline Elementary & 77 & 29.8 \\
\hline Secondary & 98 & 38.0 \\
\hline Associate/bachelor degree & 36 & 14.0 \\
\hline \multicolumn{3}{|l|}{ Social security } \\
\hline SSI & 129 & 50.0 \\
\hline Self-employment & 20 & 7.8 \\
\hline Retirement fund & 60 & 23.2 \\
\hline $\begin{array}{l}\text { Green Card (health card for uninsured } \\
\text { people in Turkey) }\end{array}$ & 27 & 10.5 \\
\hline None & 22 & 8.5 \\
\hline Total & 258 & 100 \\
\hline
\end{tabular}

Looking at BMI classifications, $21.3 \%$ of the visually impaired participants, $17.9 \%$ of the speech impaired participants, $17.8 \%$ of the hearing impaired participants and $6.5 \%$ of the orthopaedically disabled participants were in the obese category; the difference between the 
groups was significant $(\mathrm{p}<0.05)$. It was determined that $7.7 \%$ of the total participants performed regular exercise, $16.7 \%$ sometimes performed exercise, and $75.6 \%$ did no exercise. A normal weight was found for $60 \%$ of the participants who did regular exercise, $58.1 \%$ of those who sometimes performed exercise, and $37.4 \%$ of those who did not do exercise. The differences between the groups were significant $(\mathrm{p}<0.05) \quad$ (table 3$)$.

When the daily eating habits of the participants were investigated, it was found that $86.0 \%$ ate breakfast, $79.1 \%$ ate lunch and $97.7 \%$ ate dinner. Evaluation of BMI intervals according to snacking habits showed that $68.4 \%$ of participants who ate brunch everyday were of normal weight, $66.7 \%$ of participants who had a midafternoon snack everyday were of normal weight, and $45.8 \%$ of participants who had a supper-time snack everyday were of normal weight. A significant relationship was found between BMI range and regular consumption of lunch and snacks $(\mathrm{p}<0.05)$.

Of the orthopaedically disabled participants in the sample, $32.3 \%$ were male with waist circumference in the risky range, while $35.7 \%$ of the speech impaired participants were female with waist circumference in the risky range. Just over half $(53.3 \%)$ of the hearing impaired participants were male with waist circumference $<94 \mathrm{~cm}$, and $17.8 \%$ of the hearing impaired were female with waist circumference $<80 \mathrm{~cm}$. The difference between these groups was significant $(p<0.05)$. Of the participants whose disability proportions were in the interval $76-100 \%$, $36.7 \%$ were male with waist circumference $>94 \mathrm{~cm}$, and $16.3 \%$ were female with waist circumference $>80 \mathrm{~cm}$. The same rates were $13.8 \%$ and $24.1 \%$, respectively, among participants whose disability proportions were in the interval $20 \%$ or below. These differences were significant $(\mathrm{p}<0.01)$ (table 4$)$.

Analysis of risk level of NHI scores according to gender showed that $59.2 \%$ of the male participants were in the high-risk range, $38.6 \%$ were in the intermediate-risk range, and $2.2 \%$ were in the low-risk range, while $29.7 \%$ of the female participants were in the high-risk range, $58.1 \%$ were in the intermediate-risk range, and $12.2 \%$ were in the low-risk range $(p<0.01)$. The relationship between NHI score risk levels was not significant according to the disability type of the participants in the working group $(p>0.05)$. When NHI risk status was analysed according to BMI, $88.2 \%$ of the obese participants, $51.5 \%$ of the pre-obese participants, $40 \%$ of the normal participants and $41.2 \%$ of the underweight participants were found to be in the high-risk range, and the difference between the groups was significant $(\mathrm{p}<0.01)$ (table 5).

When the median DEBQ scores were analysed in terms of gender of the participants, it was found that the median score of the women was 14 and the median score of the men was 6 . The difference between the groups was significant $(\mathrm{p}<0.01)$. When analysed in terms of disability type, it was found that the median DEBQ score was 12 for the orthopaedically disabled participants, 10 for the speech impaired participants, and 9 for the hearing impaired participants. However, the difference between the groups was not significant $(p>0.05)$. When median DEBQ scores were analysed in terms of disability proportion, the median score was 4 for the participants whose disability proportion was $>75 \%$, which was significantly smaller than that of participants whose proportions were in the other intervals $(p<0.05)$.

Table 3 BMI distribution according to disability type, disability proportion and exercise status

\begin{tabular}{|c|c|c|c|c|c|c|c|c|c|c|c|}
\hline & \multicolumn{10}{|c|}{ BMI classifications } & \multirow[b]{3}{*}{ p Value* } \\
\hline & \multicolumn{2}{|c|}{ Underweight } & \multicolumn{2}{|c|}{ Normal } & \multicolumn{2}{|c|}{ Pre-obese } & \multicolumn{2}{|c|}{ Obese } & \multicolumn{2}{|c|}{ Total } & \\
\hline & $\mathbf{n}$ & \%† & $\mathbf{n}$ & $\% †$ & $\mathbf{n}$ & \%† & $\mathbf{n}$ & $\% \dagger$ & $\mathbf{N}$ & $\% \ddagger$ & \\
\hline \multicolumn{12}{|l|}{ Disability type } \\
\hline Orthopaedic§ & 16 & 12.9 & 61 & 49.1 & 39 & 31.5 & 8 & 6.5 & 124 & 48.1 & \\
\hline Seeing§ & 0 & 0 & 16 & 26.2 & 32 & 52.5 & 13 & 21.3 & 61 & 23.6 & 0.001 \\
\hline Hearing & 0 & 0 & 24 & 53.3 & 13 & 28.9 & 8 & 17.8 & 45 & 17.4 & \\
\hline Speaking & 1 & 3.6 & 9 & 32.1 & 13 & 46.4 & 5 & 17.9 & 28 & 10.9 & \\
\hline \multicolumn{12}{|c|}{ Disability proportion } \\
\hline $0-25 \S$ & 0 & 0 & 11 & 38.0 & 16 & 55.1 & 2 & 6.9 & 29 & 11.3 & \\
\hline $26-50$ & 4 & 3.6 & 40 & 36.0 & 46 & 41.4 & 21 & 19.0 & 111 & 43.0 & 0.01 \\
\hline $51-75$ & 6 & 8.7 & 33 & 47.9 & 23 & 33.3 & 7 & 10.1 & 69 & 26.7 & \\
\hline $76-100$ & 7 & 14.3 & 26 & 53.1 & 12 & 24.5 & 4 & 8.1 & 49 & 19.0 & \\
\hline \multicolumn{12}{|l|}{ Regular exercise } \\
\hline Yes & 0 & 0 & 12 & 60.0 & 8 & 40.0 & 0 & 0 & 20 & 7.7 & 0.04 \\
\hline No§ & 16 & 8.2 & 73 & 37.4 & 78 & 40.0 & 28 & 14.4 & 195 & 75.6 & \\
\hline Sometimes & 1 & 2.3 & 25 & 58.1 & 11 & 25.6 & 6 & 14.0 & 43 & 16.7 & \\
\hline Total & 17 & 6.6 & 110 & 42.6 & 97 & 37.6 & 34 & 13.2 & 258 & 100 & \\
\hline
\end{tabular}

${ }^{*}$ Fisher exact test. Bold indicates significance.

†Line percentage.

¥Column percentage.

$\S$ The groups that make the difference.

BMI, body mass index. 
Table 4 Waist circumference according to type of disability and disability proportion

\begin{tabular}{|c|c|c|c|c|c|c|c|c|c|}
\hline & \multicolumn{8}{|c|}{ Waist circumference (cm) } & \multirow[b]{4}{*}{ p Valuet } \\
\hline & \multicolumn{4}{|c|}{ Male } & \multicolumn{4}{|c|}{ Female } & \\
\hline & \multicolumn{2}{|l|}{$<94$} & \multicolumn{2}{|c|}{$\geq 94$} & \multicolumn{2}{|c|}{$<80$} & \multicolumn{2}{|c|}{$\geq 80$} & \\
\hline & $\mathrm{n}$ & $\%$ & $\bar{n}$ & $\%$ & $\bar{n}$ & $\%$ & $\bar{n}$ & $\%$ & \\
\hline \multicolumn{10}{|l|}{ Disability type } \\
\hline Orthopaedic* & 54 & 43.5 & 40 & 32.3 & 15 & 12.1 & 15 & 12.1 & 0.026 \\
\hline Seeing* & 22 & 36.1 & 19 & 31.1 & 5 & 8.2 & 15 & 24.6 & \\
\hline Hearing $^{*}$ & 24 & 53.3 & 8 & 17.8 & 8 & 17.8 & 5 & 11.1 & \\
\hline Speaking* & 11 & 39.3 & 6 & 21.4 & 1 & 3.6 & 10 & 35.7 & \\
\hline \multicolumn{10}{|c|}{ Disability proportion } \\
\hline $0-25$ & 9 & 31.0 & 4 & 13.8 & 9 & 31.0 & 7 & 24.2 & 0.001 \\
\hline $26-50^{*}$ & 53 & 47.7 & 34 & 30.6 & 6 & 5.4 & 18 & 16.2 & \\
\hline $51-75^{\star}$ & 26 & 37.7 & 17 & 24.6 & 14 & 20.3 & 12 & 17.4 & \\
\hline $76-100^{*}$ & 23 & 46.9 & 18 & 36.7 & 0 & 0 & 8 & 16.3 & \\
\hline Total & 111 & 43.0 & 73 & 28.3 & 29 & 11.2 & 45 & 17.4 & \\
\hline
\end{tabular}

Table $5 \mathrm{NHI}$ risk status according to diverse variables

\begin{tabular}{|c|c|c|c|c|c|c|c|}
\hline \multirow[b]{3}{*}{ Variable } & \multicolumn{7}{|c|}{ NHI risk status } \\
\hline & \multicolumn{2}{|c|}{ Low } & \multicolumn{2}{|c|}{ Intermediate } & \multicolumn{2}{|c|}{ High } & \multirow[b]{2}{*}{ p Value } \\
\hline & $\bar{n}$ & $\%$ & $\bar{n}$ & $\%$ & $\bar{n}$ & $\%$ & \\
\hline \multicolumn{8}{|l|}{ Gender } \\
\hline Male & 4 & 2.2 & 71 & 38.6 & 109 & 59.2 & \\
\hline Female & 9 & 12.2 & 43 & 58.1 & 22 & 29.7 & $0.001 \dagger$ \\
\hline \multicolumn{8}{|l|}{ Marital status } \\
\hline Married & 1 & 0.7 & 59 & 43.4 & 76 & 55.9 & \\
\hline Single & 12 & 12.0 & 45 & 45.0 & 43 & 43.0 & $0.002 \ddagger$ \\
\hline Widowed* & 0 & 0 & 10 & 45.5 & 12 & 54.5 & \\
\hline \multicolumn{8}{|l|}{ Disability type } \\
\hline Orthopaedic & 10 & 8.1 & 63 & 50.8 & 51 & 41.1 & \\
\hline Seeing & 1 & 1.6 & 23 & 37.7 & 37 & 60.7 & $0.078 \ddagger$ \\
\hline Hearing & 1 & 2.2 & 17 & 37.8 & 27 & 60.0 & \\
\hline Speaking & 1 & 3.6 & 11 & 39.3 & 16 & 57.1 & \\
\hline \multicolumn{8}{|c|}{ Disability proportion } \\
\hline $0-25$ & 0 & 0 & 19 & 65.5 & 10 & 34.5 & \\
\hline $26-50^{\star}$ & 3 & 2.7 & 37 & 33.3 & 71 & 64.0 & $0.003 \ddagger$ \\
\hline $51-75$ & 5 & 7.2 & 35 & 50.7 & 29 & 42.0 & \\
\hline $76-100$ & 5 & 10.2 & 23 & 46.9 & 21 & 42.9 & \\
\hline \multicolumn{8}{|c|}{ BMI classification } \\
\hline Underweight & 0 & 0 & 10 & 58.8 & 7 & 41.2 & \\
\hline Normal $^{*}$ & 11 & 10.0 & 55 & 50.0 & 44 & 40.0 & $0.001 \ddagger$ \\
\hline Pre-obese & 0 & 0 & 47 & 48.5 & 50 & 51.5 & \\
\hline Obese & 2 & 5.9 & 2 & 5.9 & 30 & 88.2 & \\
\hline
\end{tabular}

Analysis of median DEBQ scores in terms of BMI showed that the underweight participants were in the interval of $8.4 \pm 6.6$, the normal participants were in the interval of $8.8 \pm 8.5$, the pre-obese participants were in the interval of $9.3 \pm 8.5$, and the obese participants were in the interval of $7.8 \pm 10.0$. The difference between the groups was not significant $(\mathrm{p}>0.05)$ (table 6$)$.
When the median NHP scores were analysed according to gender, it can be seen in table 6 that the median score was 10.5 for the men and 5.2 for the women. The difference between the groups was not significant $(p>0.05)$. When the median NHP score was analysed according to disability type, a significantly higher score (31.5) was found for orthopaedically disabled 
Table 6 DEBQ score and NHP score distribution according to diverse variables

\begin{tabular}{|c|c|c|c|c|c|}
\hline Variable & Min & Median & $\operatorname{Max}$ & $A M \pm S D$ & p Value \\
\hline \multicolumn{6}{|l|}{$D E B Q$} \\
\hline \multicolumn{6}{|l|}{ Gender } \\
\hline Male & 0 & 6 & 32 & $7.5 \pm 8.2$ & \\
\hline Female & 0 & 14 & 39 & $12.0 \pm 8.7$ & $0.001 \dagger$ \\
\hline \multicolumn{6}{|l|}{ Marital status } \\
\hline Married & 0 & 5.5 & 27 & $7.6 \pm 8.0$ & \\
\hline Single & 0 & 12.5 & 30 & $10.2 \pm 8.1$ & $0.07 \ddagger$ \\
\hline Widowed & 0 & 6 & 39 & $10.1 \pm 12.2$ & \\
\hline \multicolumn{6}{|l|}{ Disability type } \\
\hline Orthopaedic & 0 & 12 & 32 & $9.1 \pm 7.7$ & \\
\hline Seeing & 0 & 0 & 39 & $7.2 \pm 8.9$ & $0.18 \ddagger$ \\
\hline Hearing & 0 & 9 & 30 & $9.4 \pm 9.7$ & \\
\hline Speaking & 0 & 10 & 27 & $10.1 \pm 9.5$ & \\
\hline \multicolumn{6}{|c|}{ Disability proportion } \\
\hline $0-25$ & 0 & 12 & 29 & $11.3 \pm 9.0$ & \\
\hline $26-50$ & 0 & 12 & 39 & $9.5 \pm 9.6$ & $0.021 \ddagger$ \\
\hline $51-75$ & 0 & 11 & 23 & $9.2 \pm 7.7$ & \\
\hline $76-100^{*}$ & 0 & 4 & 15 & $5.5 \pm 5.8$ & \\
\hline \multicolumn{6}{|c|}{ BMI classification } \\
\hline Underweight & 0 & 12 & 18 & $8.4 \pm 6.6$ & \\
\hline Normal & 0 & 7 & 32 & $8.8 \pm 8.5$ & $0.60 \ddagger$ \\
\hline Pre-obese & 0 & 12 & 30 & $9.3 \pm 8.5$ & \\
\hline Obese & 0 & 0 & 39 & $7.8 \pm 10.0$ & \\
\hline \multicolumn{6}{|l|}{ NHP } \\
\hline \multicolumn{6}{|l|}{ Gender } \\
\hline Male & 0 & 10.5 & 71.0 & $20.2 \pm 20.9$ & \\
\hline Female & 0 & 5.2 & 55.2 & $13.9 \pm 17.1$ & $0.050 \dagger$ \\
\hline \multicolumn{6}{|l|}{ Marital status } \\
\hline Married* & 0 & 5.2 & 71.0 & $13.3 \pm 19.2$ & \\
\hline Single & 0 & 18.4 & 65.7 & $21.9 \pm 19.5$ & $0.001 \ddagger$ \\
\hline Widowed & 0 & 34.2 & 65.7 & $33.7 \pm 16.5$ & \\
\hline \multicolumn{6}{|l|}{ Disability type } \\
\hline Orthopaedic* & 0 & 31.5 & 65.7 & $32.1 \pm 18.3$ & \\
\hline Seeing & 0 & 2.6 & 71.0 & $5.7 \pm 12.9$ & $0.001 \ddagger$ \\
\hline Hearing & 0 & 2.6 & 71.0 & $6.0 \pm 11.5$ & \\
\hline Speaking & 0 & 2.6 & 18.4 & $4.9 \pm 6.6$ & \\
\hline \multicolumn{6}{|c|}{ Disability proportion } \\
\hline $0-25^{a}$ & 0 & 2.6 & 39.4 & $7.1 \pm 10.5$ & \\
\hline $26-50^{a}$ & 0 & 2.6 & 71.0 & $10.5 \pm 17.3$ & $0.001 \ddagger$ \\
\hline $51-75^{\mathrm{b}}$ & 0 & 15.7 & 65.7 & $22.0 \pm 19.7$ & \\
\hline $76-100^{C}$ & 0 & 39.4 & 65.7 & $37.6 \pm 15.6$ & \\
\hline \multicolumn{6}{|c|}{ BMI classification } \\
\hline Underweight $^{a}$ & 0 & 34.2 & 65.7 & $33.1 \pm 16.9$ & \\
\hline Normal $^{\mathrm{a}}$ & 0 & 15.7 & 71.0 & $23.5 \pm 21.6$ & $0.001 \ddagger$ \\
\hline Pre-obese ${ }^{b}$ & 0 & 5.2 & 65.7 & $12.9 \pm 16.8$ & \\
\hline Obese $^{b}$ & 0 & 5.2 & 65.7 & $10.2 \pm 16.3$ & \\
\hline
\end{tabular}

*Groups that make the difference.

†Mann-Whitney U Test.

$\ddagger$ Kruskal Wallis Test.

$a, b$ and $c$ are different from each other. Bold indicates significance.

AM, arithmetic mean; BMI, body mass index; DEBQ, Dutch Eating Behaviour Questionnaire; NHP, Nottingham Health Profile.

participants than for participants with other types of disability $(p<0.01)$. The difference between the others was not significant $(p>0.05)$. Analysis of median NHP score according to BMI showed that the average scores of the underweight and normal weight participants were significantly higher than those of the pre-obese and obese participants $(\mathrm{p}<0.01)$ (table 6$)$.

When the median scores obtained for the NHP subscale, social isolation, were analysed according to disability type, the median for orthopaedically disabled participants was 20 , which was significantly higher than for the other types of disability $(p<0.01)$. While the median score of the participants whose disability proportion was $25 \%$ or below did not differ significantly from those whose disability proportion was in the range 26-50\% ( $p>0.05)$, it is significantly smaller than that of the participants whose disability proportion was $50 \%$ or above $(\mathrm{p}<0.01)$.

\section{DISCUSSIONS}

Obesity is a complex disease which involves many psychological problems in addition to eating disorders, metabolic disorders and lack of physical activitiy. ${ }^{23}$ It has become an important issue on which emphasis must be placed because of its gradual proliferation and early deaths due to medical complications over the last 15 years. ${ }^{24} 25$ The WHO reported that the prevalence of obesity increased by $50 \%$ and reached 300 million in the world between 1995 and 2000. ${ }^{26}$ The relationship of obesity to morbidity and mortality has become a public health issue on a global scale, meaning that increasing attempts to prevent obesity must be obligatory.

We observed that, in our sample, $42.6 \%$ of the disabled were 40 years old or more, and there was no significant relationship between distribution of disability type and age. However, when looked at by specific disability type, an increase in parallel with age was observed for disability proportion in the visually impaired, hearing impaired and speech impaired participants, which showed rates that all went up, although the number of orthopaedically disabled participants aged 40 years old or more was few. When age was considered according to disability proportion, it could be seen that disability proportion increased in parallel with the age. When disability proportion was analysed in terms of age in the Turkey Disability Survey, it was noticed that disability proportion rose in parallel with age in the orthopaedically disabled, visually impaired and hearing impaired. ${ }^{7}$ Increases in disability proportion in parallel with age for disabled people may be due to deterioration in visual, hearing and speaking function.

In our study, no significant relationship was found between educational level and disability type. The rate of illiterate people or people who are literate but did not graduate from elementary school was $19.4 \%$ for orthopaedic disability, $16.4 \%$ for visual impairment, and $21.4 \%$ for speech impairment. In the Turkey Disability Survey, the rate of illiterate people who were 6 years old or more was $36.3 \%$ in the orthopaedically disabled, visually impaired, hearing impaired, speech impaired and mentally disabled. This rate is $12.9 \%$ in the total population. Therefore, the rate of illiterate people among the 
orthopaedically disabled, visually impaired, hearing impaired, speech impaired and mentally disabled is higher than that in the total population: while nearly one in ten of the total population was illiterate, this number increased to four in ten for the disabled. When the educational level was analysed, no significant difference was found between the rate of the participants who graduated from elementary school and participants who were orthopaedically disabled, visually impaired, hearing impaired, speech impaired, mentally disabled and who had chronic illnesses.

It was seen in our sample that $46.8 \%$ of the orthopaedically disabled participants were unemployed, students or housewives, $24.2 \%$ were self-employed, $15.3 \%$ were workers, $5.6 \%$ were civil servants and $8.1 \%$ were retired. In the Turkey Disability Survey, the rate of participation in the labour force of orthopaedically disabled, visually impaired, hearing impaired, speech impaired and mentally disabled people was $21.7 \% .^{7}$ The results are compatible with the findings of our study.

It was determined in our study that $50 \%$ of the participants had the security of SSI, $23.3 \%$ had the security of a retirement fund, $10.5 \%$ had the security of a Green Card (health card for uninsured people in Turkey), $7.8 \%$ were self-employed, but $8.5 \%$ had no social security. In the Turkey Disability Survey, it was observed that $47.6 \%$ of the orthopaedically disabled, visually impaired, hearing impaired, speech impaired and mentally disabled participants had social security. It is seen that $56.6 \%$ of orthopaedic, seeing, hearing, speaking and mentally disabled people of the overall population were registered with SSI, $19.3 \%$ were registered with a retirement fund, and $24.2 \%$ were registered with a selfemployment fund. ${ }^{7}$ These are compatible with the results of our study.

The prevalence of obesity was found to be $13.2 \%$ in our study. Among non-disabled people this rate varies, reported to be $44.4 \%$ in a study in $2000,22 \%$ in 1999 , $16.4 \%$ in 1990 , and $38.2 \%$ in the study of Fouad et $a l^{2}{ }^{27-29}$ In the study of Turan $e t a l^{13}$ obesity prevalence was found to be $13.7 \%$ in vocational high school students. In a study carried out with disabled students aged between 13 and 22 in Japan, body fat proportion was evaluated, and it was found that $18.5 \%$ of students had body fat proportions above $30 \% .{ }^{9}$ While it is predicted that obesity prevalence ranges between $25 \%$ and $31 \%$ in disabled adults in the USA, it is anticipated that the rate in people with no disability ranges between $15 \%$ and $19 \% .{ }^{30}$ Although our results are compatible with these other studies, it is only a sample and does not represent the entire society that is at risk.

The relationship between disability type and obesity status was found to be significant. Obesity prevalence was found to be $21.3 \%$ in visually impaired participants, $17.9 \%$ in speech impaired participants, $17.8 \%$ in hearing impaired participants and $6.5 \%$ in orthopaedically disabled participants. In a study conducted on disabled students in Japan, obesity prevalence was found to be significantly lower in orthopaedically disabled participants than in participants with other types of disability. Insufficient nourishment is thought to be the reason of this difference. ${ }^{9}$ The result is compatible with the findings of our study.

Even though the relationship between obesity status and eating breakfast and dinner regularly was not found to be significant, obesity status was lower in disabled participants who were eating three main meals every day. The study of Kuyumcu ${ }^{31}$ reported that there was no significant relationship between obesity status and the regular consumption of three main meals every day, which is similar to our study. The study of Sözen $e t a l^{32}$ revealed no relationship between BMI and skipping meals, which differs from our study. This is thought to result from different samples. In the study of Deveci et $a l^{33}$ no statistical relationship was reported between obesity status and skipping a meal.

In our study, obesity prevalence was found to be $13.7 \%$ in disabled participants who ate lunch every day, $27.3 \%$ in those who ate no lunch, and $37.8 \%$ in those who sometimes ate lunch. Obesity prevalence was significantly lower in the disabled participants who ate lunch every day. While the relationship between obesity status and consumption of snacks was found to be significant, the relationship between obesity status and consumption of mid-afternoon and mid-morning snacks was negative and the consumption of a supper-time snack was positive. This is thought to result from the types, amounts and timing of supper-time snacks. In the study of Turan et $a l,{ }^{13}$ skipping breakfast came first, with $23.3 \%$ of participants who skipped meals and $54.7 \%$ of participants who did not eat snacks between main meals. In this study, it was reported that there was a significant relationship between obesity prevalence and skipping meals and that obesity incidence was higher in participants who skipped meals.

In our study, $7.7 \%$ of the sample took regular exercise, and obesity is not observed in people who take regular exercise. It was seen that $14 \%$ of participants who sometimes took exercise and $14.4 \%$ of participants who did not take any exercise were obese, and the relationship between exercise and obesity status was found to be significant. Karacan et $a l^{34}$ found out that taking regular exercise affects BMI positively downstream.

Analysis of risk level classification of NHI scores in terms of gender showed that $59.2 \%$ of the men were in the high-risk range, $38.6 \%$ were in the intermediate-risk range, and $2.2 \%$ were in the low-risk range. This compares with $29.7 \%$ of the women in the high-risk range, $58.1 \%$ in the intermediate-risk range, and $12.2 \%$ in the low-risk range $(p<0.01)$. When the risk level of nutrition habits was analysed in terms of marital status, it was observed that $55.9 \%$ of the married participants, $54.5 \%$ of the widowed participants and $43 \%$ of the single participants were in the high-risk range $(\mathrm{p}<0.05)$.

When the risk level classification of NHI scores of the sample was analysed in terms of disability proportion, 
$64 \%$ of participants whose disability proportion was in the $26-50 \%$ interval were in the high-risk range compared with $34.5 \%$ of those whose disability proportion was below $25 \%(\mathrm{p}<0.05)$.

The affective eating behaviour sub-scale of the DEBQ was used to evaluate emotional conditions of the sample. In the literature, it is accepted that there is a mutual interaction between state of mind and eating habits, and eating behaviour may change according to feelings such as anxiety, joy, sorrow, anger and depression. ${ }^{35} 36$

When the median DEBQ score was analysed in terms of gender, it was found out that the median score was 14 for female participants and 6 for male participants, with the difference between the groups being significant $(p<0.01)$. We speculate that this difference may be because women's feelings change more often than men's. When the median DEBQ score was analysed in terms of marital status, they were found to be 5.5, 12.5 and 6 for married, single and widowed, respectively. The median score of the single participants was significantly higher than of the widowed and married participants $(p<0.05)$. We assume that the single participants' feeling lonely might account for this difference.

When the median DEBQ score was analysed in terms of disability type, orthopaedically disabled participants had a score of 12, the speech impaired had a score of 10 , and the hearing impaired had a score of 9 , and the difference between them was not significant. Analysis of the median DEBQ score in terms of disability proportion showed it was 4 for participants whose disability proportion was above $75 \%$, which was significantly lower than for those whose disability proportions were in the other ranges $(p<0.05)$. It is believed that this difference may be because those whose disability proportion is in this range are not left alone, as they are in need of special care.

When the median score of NHP was analysed in terms of BMI intervals, it was seen that the mean scores of the underweight and normal weight participants were higher than those of the pre-obese and obese participants $(\mathrm{p}<0.01)$.

Analysis of median NHP score in terms of marital status revealed a score of 34.2 for widowed participants, 18.4 for single participants, and 5.2 for married participants $(p<0.01)$. This might reflect the loneliness of the single and widowed. When the median NHP score was analysed in terms of gender, the score of the orthopaedically disabled participants was significantly higher than that of participants with other types of disability. The difference between the others was not significant $(p>0.05)$. It is believed that this difference may be because orthopaedically disabled participants have some muscle and bone pain.

The difference between scores obtained for the subscale of social isolation was not found to be significant $(p>0.05)$. Analysis of average scores by age group showed that participants aged between 25 and 29 (mean 23.6 \pm 21.7$)$ had significantly higher scores than those in the 20-24 and 40 or above age groups. When the participants' habits of taking exercise were analysed, the difference between participants who took regular exercise and those who sometimes took exercise or did no exercise was significant.

Yolgösteren compared the NHP scores of disabled people who did or did not do sport. ${ }^{37}$ It was found that doing sport led to higher total scores and quality of life improved remarkably. Evaluation in terms of sub-groups of NHP revealed that social isolation was a factor that affected group members not doing any sport. Social isolation of individuals who do sport declines as their social acknowledgement increases, a result similar to the findings of our study.

\section{CONCLUSIONS}

In our study, it is seen that obesity prevalence in physically disabled adults living in the city centre of Malatya, Turkey was $13.2 \%$. The biggest obesity prevalence $(21.3 \%)$ according to disability type was found in visually impaired participants $(p<0.01)$. However, the frequency of male and female participants whose waist circumferences were considered to be in the risky range was greatest in orthopaedically disabled participants $(p<0.05)$. It was found that $19 \%$ of participants whose disability proportions were in the range $26-50 \%$ were obese $(p<0.05)$. Obesity prevalence increased among participants who did not engage in regular exercise $(p<0.05)$.

As obesity emerges as an important health problem in developed and developing countries, with increasing prevalence, it has an even greater negative effect on the quality of life of disabled people. We hope that our study draws attention to obesity in disabled people, so that more research is carried out in many countries around the world.

Twitter Follow Çiğdem Bozkır at @cigdembozkir

Acknowledgements Our manuscript was edited by scribendi.com.

Funding This research received no specific grant from any funding agency in the public, commercial or not-for-profit sectors.

Competing interests None declared.

Patient consent Obtained.

Provenance and peer review Not commissioned; externally peer reviewed.

Data sharing statement No additional data are available.

Open Access This is an Open Access article distributed in accordance with the Creative Commons Attribution Non Commercial (CC BY-NC 4.0) license, which permits others to distribute, remix, adapt, build upon this work noncommercially, and license their derivative works on different terms, provided the original work is properly cited and the use is non-commercial. See: http:// creativecommons.org/licenses/by-nc/4.0/

\section{REFERENCES}

1. World Health Organization. Obesity: preventing and managing the global epidemic. Technical report 894. Geneva: WHO, 2000:256.

2. Program of Struggle and Control with obesity in Turkey. T.R. Ministry of Health Basic Health Services General Directorate. 2010-2014. http://beslenme.gov.tr/content/files/home/turkiye_obezite_sismanlik_ ile_mucadele_ve_kontrolprogrami_2010_2014.pdf

3. Serter R. Atlas of obesity. 1st print. Ankara: Karakter Color, 2004. 
4. Eren i, Erdi Ö. The frequency of psychiatric deficiencies on obese patients. Clin Psychiatry J 2003;6:152-7.

5. Koca C. Briefing Report of Unburdened City Planning. İstanbul, 2010.

6. WHO. Disability, Prevention and Rehabilitation. Technical Report Series, 668, Geneva: World Health Organisation, 1981.

7. State Institute of Statistics. Turkey Disability Survey. 2002. http://kutuphane.tuik.gov.tr/pdf/0014899.pdf

8. Caterson ID, Broom J. Pocket picture guide obesity. 1st edn. London: Mosby International, 2001.

9. Ouwens MA, van Strein T, van der Stoak C. Tendency toward overeating and restraint as predictors of food consumption. Appetite 2003;40:291-8.

10. State Institute of Statistics. http://report.tuik.gov.tr (accessed 4 May 2011).

11. Suzuki M, Saitoh S, Tasaki Y, et al. Nutritional status and daily physical activity of handicapped students in Tokyo metropolitan schools for deaf, blind, mentally retarded and physically handicapped individuals. Am J Clin Nutr 1991;54:1101-11.

12. Demirezen E, Çoşansu G. Evaluation of nutritional habits on adolescent students. Sted 2005;14.

13. Turan T, Ceylan SS, Çetinkaya B, et al. Investigation of obesity prevalence and nutritional habits of vocational high school students. Protect Med Sci Bull 2009;8:5-12.

14. Van Strein T, Frijters J, Bergers G, et al. The Dutch eating behaviour questionnaire (DEBQ) for assesment of restrained, emotional and external eating behaviour. Internat $J$ Eat Disorder 1986;5:295-315.

15. Bozan N. Validity and reliability test of the Dutch Eating Behaviour (DEBQ) on Turkish University Students. Master's Thesis, Başkent University Institute of Health Sciences Program of Nutrition and Dietetic. 2009. https://tez.yok.gov.tr/UlusalTezMerkezi/ tezSorguSonucYeni.jsp (accessed 10 Feb 2011).

16. Baum FE, Cooke RD. Community-health needs assessment: use of the Nottingham Health Profile in an Australian study. Med $J$ Aust 1989;150:581-90.

17. Küçükdeveci AA, McKenna SP, Kutlay S, et al. The development and psychometric assessment of the Turkish version of the Nottingham Health Profile. Int J Rehabil Res 2000;23:31-8.

18. Wiklund I. The Nottingham Health Profile: a measure of health-related quality of life. Scand J Prim Health Care 1990;1:15-18.

19. Bowling ANN. Measuring health. Milton Keynes: Open University Press, 1991:65-6.

20. Badia X, Alonso J, Brosa M, et al. Reliability of the Spanish version of the Nottingham Health Profile in patients with stable end-stage renal disease. Soc Sci Med 1994;38:153-8.

21. WHO. Meeting of Ministers of Europe about the Struggle with Obesity. Istanbul, 2006. http://www.t-hasak.org/Obezite.pdf (accessed 12 Apr 2011).

22. Baysal A. Diet handbook. 4th print. Ankara: Hatiboğlu Publishing House, 2002.
23. Keskin G, Engin E, Dulgerler G. Eating attitude in the obese patients: the evaluation in terms of relational factors. $J$ Psychiatr Ment Health Nurs 2010;17:900-8.

24. Blackburn GL, Kanders BS. Medical evaluation and treatment of the obese patient with cardiovascular disease. Am J Cardiol 1987;60:55G-8G.

25. Kaya A, Gedik VT, Bayram F, et al. Diagnosis and Treatment Guide for Doctors about Hypertension, Obesity and Lipid metabolism. Turkey Endocrinology and Metabolism Association, 2009:57.

26. Schooling CM, Lam TH, Li ZB, et al. Obesity, physical activity and mortality in a prospective chinese elderly cohort. Arch Intern Med 2006;166:1498-504.

27. Hatemi H, Turan N, Arık N, et al. Results of Turkey obesity and hypertension Scanning (TOHTA). J Orientat Endocrinol 2002;11 (Appendix 1):1-16.

28. Sansoy V, Onat A. Obesity, abdominal obesity, determiners and results. 2007. http://tekharf.org/images/bolum8.pdf (accessed 11 Jan 2011).

29. Fouad MF, Rastam S, Ward KD, et al. Prevalence of obesity and its associated factors in Allepo, Syria. Prev Control 2006;2:85-94.

30. Rejeski JW, Marsh PA, Chelmo E, et al. Obesity, intentional weight loss and physical disability in older adults. Obes Rev 2010;11:671-85.

31. Kuyumcu G. Body Mass Index and Some Related Factors on 1st and 6th grade Students at Ankara University Faculty of Medicine. Thesis of Specialization. Ankara University Faculty of Medicine Department of Public Health. 2007. https://tez.yok.gov.tr/ UlusalTezMerkezi/tezSorguSonucYeni.jsp (accessed 12 Jan 2011).

32. Sözen S, Bilir N, Yıldız AN, et al. Nutritional habits of employees in a workplace active in metal sector. Community Med Bull 2009;28. https://tez.yok.gov.tr/UlusalTezMerkezi/tezSorguSonucYeni.jsp

33. Deveci SE, Güler H, Demet M, et al. Obesity prevalence on the police officers who applied to Polyclinic of Community Medicine of Elazığ Security Directorate. Firat Univ J Health Knowled 2004:18:223-8.

34. Karacan S, Colakoğlu FF, Erol AE. The effect of aerobics exercise on obese middle-aged females and females in the menopause period on some physical suitability values. Erciyes Univ J Health $\mathrm{Sci}$ 2004:13:35-42.

35. Maskarinec G, Takata Y, Pagano I, et al. Trends and dietary determinants of overweight and obesity in a multiethnic population. Obesity (Silver Spring) 2006;14:717-26.

36. Özgür $G$, Gümüş $A B$, Palaz $C$. Investigation of depressive symptom levels and the effective factors on obese individuals. Atatürk Univ $J$ Nurs Grad School 2008;11:3.

37. Yolgösteren E. In-water and out-water exercise activity on patients with post-operative backache. Thesis of Specialization. Uludağ University Faculty of Medicine Department of Physical Medicine and Rehabilitation. 2006. https://tez.yok.gov.tr/UlusalTezMerkezi/ tezSorguSonucYeni.jsp (accessed 12 Jan 2011). 